\title{
Integrated Application of Multiphysical Methods in Landfill dam Monitoring
}

\author{
Lucca Martins Franco*, Emanuele Francesco La Terra, Sergio Luiz Fontes, Observatório Nacional
}

Copyright 2021, SBGf - Sociedade Brasileira de Geofísica

This paper was prepared for presentation during the $17^{\text {th }}$ International Congress of the Brazilian Geophysical Society held in Rio de Janeiro, Brazil, 16-19 August 2021.

Contents of this paper were reviewed by the Technical Committee of the $17^{\text {th }}$ International Congress of the Brazilian Geophysical Society and do not necessarily represent any position of the SBGf, its officers or members. Electronic reproduction or storage of any part of this paper for commercial purposes without the written consent of the Brazilian Geophysical Society is prohibited.

\section{Abstract}

This project aims the adaptation of electrical and electromagnetic geophysical methods for the purpose of monitoring containment landfill dams. This work is justified by the high number of incidents involving the breaking of earth and rockfill dams in the last decades. We propose the combined use of electric resistivity tomography (ERT), induced polarization (IP) and ground penetrating radar (GPR) methods as indirect, noninvasive, mechanisms to verify the structural and hydrodynamic stability conditions of the dike and dam foundation. This approach is complementar to the traditional instrumentation, which involves the use of piezometers, level displacement measurers, as well as visual inspections. The test area, in which the geophysical survey was carried out, is an earth dam located in Rio de Janeiro State, Brazil. The reservoir in this case is intended for water containment with industrial purposes in an oil refinery. Interpretation of the available data has been proved to be efficient for the proposed purpose and the authors believe that the methodology could be applied to landfill dams for any type of reservoir, with main interest being the ore tailings dams.

\section{Introduction}

The first known cases of earth dam failure took place at 4800 BC, in ancient Egypt (Thomas 1976). Nevertheless, similar incidents kept happening trough the course of history despite of all technological improvments and setting of safety standards. In the past two decades the increased number of cases enwraping the rupture of ore tailing dams in Brazil, especialy in Minas Gerais state, has concerned experts from different fields. Hence, modern monitoring methods are beeing widespread and incorporated into academical studies, in a attempt to complement the usual auscultation procedures, with reliable and non-invasive technics (Al-Fares, 2011; Case, 2012; Di \& Wang, 2009; Kemna et al., 2004(a); Kemna et al., 2012(b); Lin et al., 2013; Minsley et al., 2010). The application of geophysical methods for the purpose of monitoring containment dams is a practice that, although recent, has become a common and suitable procedure in private and public sectors.

The present work, however, proposes an approach to data acquisition and analysis that differs from many others, since it introduces and demonstrates the benefits of an integrated application transiting between electrical and electromagnetic methods.

Here it is proposed the use of electrical resistivity tomography (ERT), induced polarization (IP) and ground penetration radar (GPR) in earth dams, in order to observe the performance of the soil applied in the landfill structure, besides piezometer and level displacement data, identifying potential regions of liquefaction, cracks and discontinuities. The project aims to test the viability of the methodology for the proposed purpose, seeking to identify ERT and IP field arrangements, parameter settings and processing techniques that are best adapted to the study of dams.

The research took place in a earth dam, intended for water storage, located in the countryside of Rio de Janeiro state (Figure 1). For industrial purposes, the structure dams water from small river, in a 6 million $\mathrm{m}^{3}$ reservoir. Two data acquisition campaigns were carried out, in October of 2019 and March of 2020. Seeking for significative temporal and anomalous internal changes inside the dam's embarkment and jambs, the results obtained in both campaigns were compared, aiming to determinate the influence of pluviometric oscillation and reservoir level in the structure's integrity. The inverted bidimensional ERT and IP sections were analised by means of piezometric comparison, wich allowed the delimitation of conductive regions along with the water level in subsurface. The sazonal/temporal anomalies, between october and march, were calculated trough timelapse inversion method, as elucidated ahead.

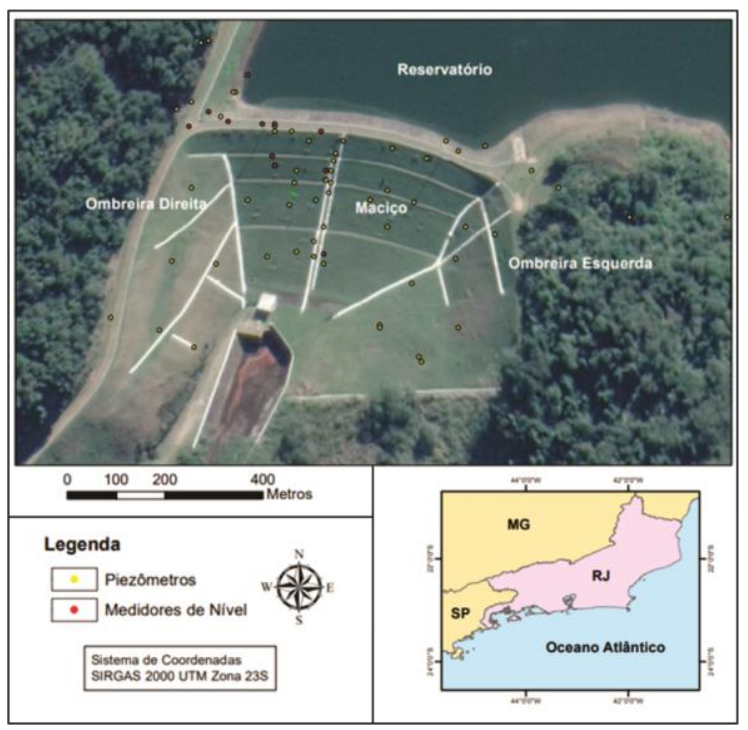

Figure 1 - Landfill dam map, with piezometers. 
A confidentiality agreement was binded with the engineering team responsible for the landfill dam at matter and, therefore, we've chose to ommit it's location and identification.

\section{Method}

\section{Data Acquisition}

Electrical resistivity tomography (ERT) and induced polarization (IP) data, with dipole-dipole array, were collected in two acquisition campaigns (Figure 2). The first campaign was conducted in the period between $07 / 10 / 2019$ and 18/10/2019. The second campaign was conducted between 06/03/2020 and 09/03/2020. GPR data was acquired only in the first campaign (Figure 3 ). For altimetric correction and line georeferencing, geodesical positioning data was collected with a GNSS receiver.

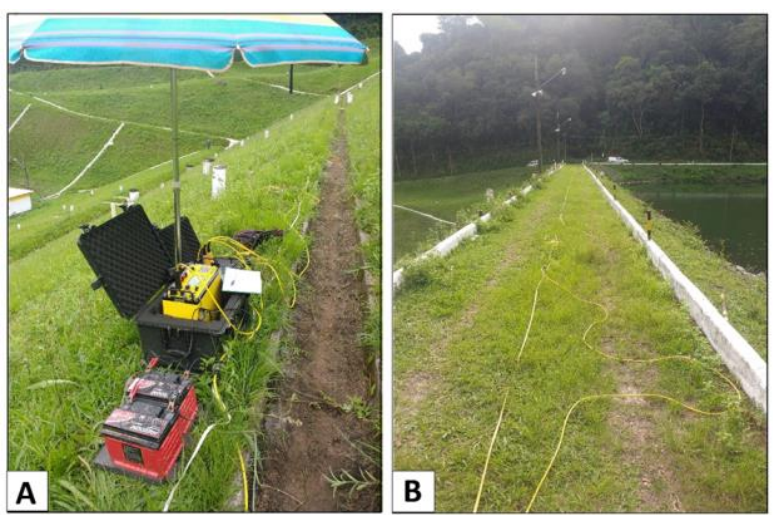

Figure 2 - (A) Supersting R8/IP in operation during ERT acquisition; (B) Multi-electrode cable set above the dam's crest.

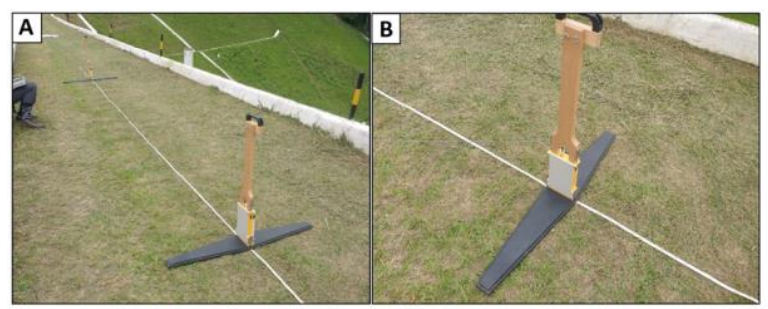

Figure 3 - (A) MALA ProEx GPR equipment, (B) with pair of unshielded $100 \mathrm{MHz}$ antennas, used during field acquisition campaign.

ERT and IP data were collected in seven identical profile lines, with the first six (Lines 1 to 6 ) parallel to the dam crest and the last one (Line 7) perpendicular to it. The profiles, therefore, have crossed the left and right shoulders, in addition to traversing the dam massif. For this survey, we have used the Supersting R8 Earth Resistivity/IP/SP equipment, (Advanced Geosciences AGI), along with a set of multi-electrode cables, polarizable and non-polarizable electrodes. GPR data acquisition was performed only in the first campaign, in October 2019. Six lines parallel to the dam crest (Line 1 to 6) were performed, with the first one positioned immediately above the crest of the massif and the last one above the foundation. Mala's ProEx System equipment was used, coupled with a pair of $100 \mathrm{MHz}$ unshielded antennas.

Furthermore, the engineering team responsible for the dam, provided us with piezometric data for the period when the acquisition campaigns were carried out and which served as a basis for interpretation and analysis of the collected information. Geotechnical information and inspection reports of the dam were also provided.

\section{Data Processing}

To analyze the distribution of soil apparent resistivity and chargeability, in subsurface, several tomograms (pseudosections) were generated in Earth Imager 2D Inversion software. Altimetric surface information and the water table level were displaced in each profile, along with geoelectrical information. A data processing routine was used, which aimed at removing unwanted noisy information and decreasing the RMS. For this purpose, the misfit histogram was edited as a function of the total amount of data. The misfit is defined as the ratio: (calculated data - measured data) / (measured data), where the measured data refers to the apparent resistivity. Misfit values greater than $50 \%$ can generally be considered an error.

GPR raw data was adjusted and processed in MALA RadExplorer software. Time-depth conversion was performed, and specific filters were applied for better highlighting of the structural features of the embankment dikes of the dam. GNSS information was treated and then, converted to GIS format.

\section{Piezometry Analysis}

The piezometry analysis consisted, firstly, of a comparison between profiles, transversal to the dam axis, showing the water table inside the massif at different times. This technique aims to verify the variation of the water level within the compacted embankment between the months in which geophysical surveys were performed, i.e., October/2019 and March/2020. For this purpose, it was essential to check the rainfall values for the months in question.

In a second moment, a comparison was made of graphs plotting piezometric height and relative reservoir level. In this case, the height refers to the difference between the well top and the water table.

\section{ERT Time-Lapse Inversion}

The application of this inversion technique allowed a comparative analysis of the hydraulic performance inside the dam between winter and summer, in view of the variation in pluviometric regime between both seasons. The technique allows the identification of unstable regions, with a temporal pattern of anomalous electrical resistivity variation, wich may correspond to leakage regions inside landfill dikes. 


\section{Results}

\section{ERT 2D Inverted Tomograms}

From the ERT data processing, 21 bidimensional electrical resistivity sections were made. The water table of the dam massif and abutments, verified by piezometric readings during the data acquisition period, was indicated in each of the sections. Maps were also generated in GIS environment, referencing the positioning of piezometers and the exact locations where the geophysical tests were performed.

The following images (Figures 3 and 4 ) displays two 2D resistivity sections, obtained and processed in this project. These correspond, respectively, to the dam crest and the line that passes over the dam foundation.

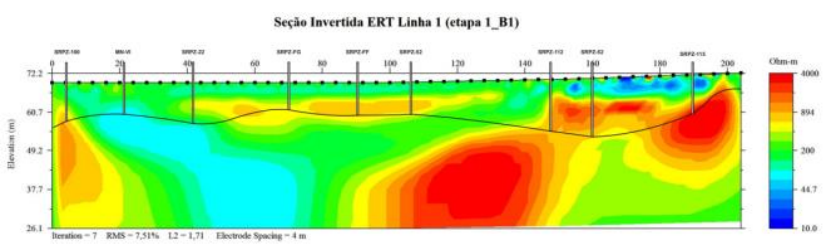

Figure 4 - ERT 2D resistivity tomogram of the dam's creast, during the first acquirement campaign.

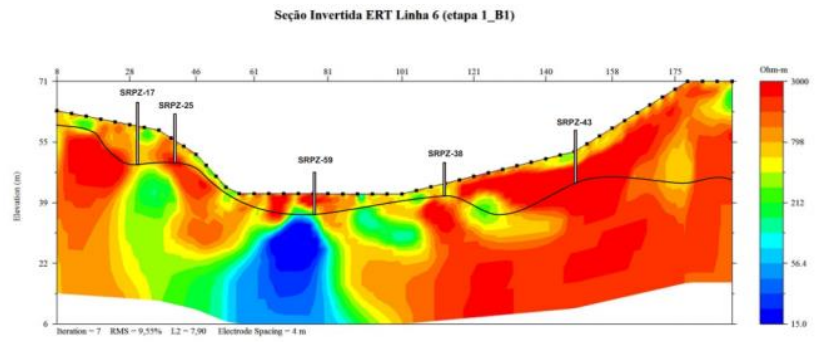

Figure 5 - ERT 2D resistivity tomogram of the dam's foundation, during the first acquirement campaign.

Based on IP acquisitions, 21 chargeability sections were also made, which are shown in the following figures (Figures 6 and 7) - with reference to the first acquisition campaign. The unit of chargeability in this case is given in $(\mathrm{mV} / \mathrm{V}){ }^{*}\left(\Omega^{*} \mathrm{~m}\right)$, since Earthlmager software multiplies the parameter of interest by the apparent resistivity.

The IP method is particularly useful in materials that present, in their constitution, conductive or semiconducting minerals, such as oxides and disseminated argillominerals (Kemna et al., 2012).

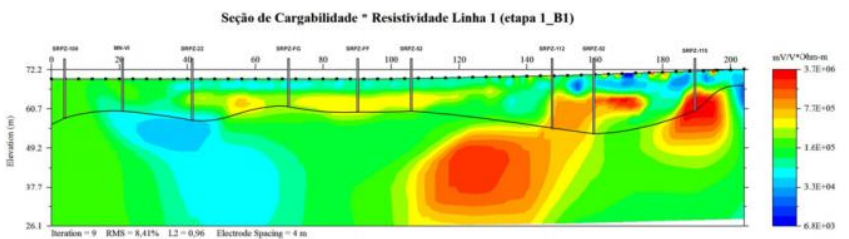

Figure 6 - IP 2D chargeability tomogram of the dam's creast, during the first acquirement campaign.

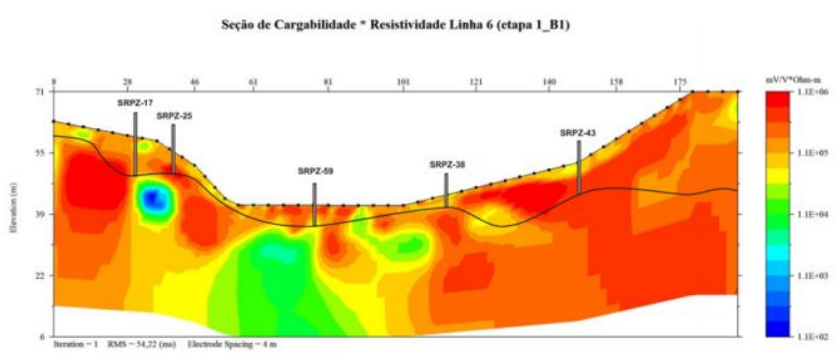

Figure 7 - IP 2D chargeability tomogram of the dam's foundation, during the first acquirement campaign.

\section{GPR}

Six parallel GPR bidimensional radagrams were generated in MALA's RadExplorer software. The following image (Figure 8) displays the $208 \mathrm{~m}$ long, creast profile.

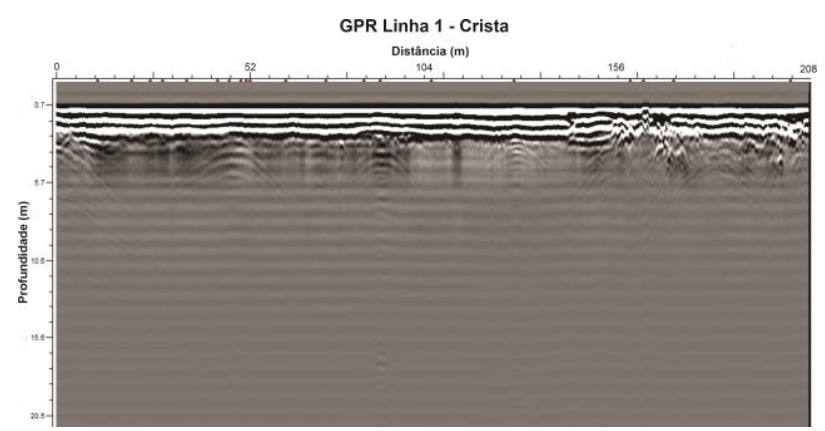

Figure 8 - Radagram of the dam crest.

\section{Piezometry}

The following schematic profile (Figure 9) refers to the water table behavior of the dam in a section perpendicular to the crest, in its central portion, with respect to piezometric height readings from seven piezometers: SRPZ-FG, SRPZFA, PZ-28, SRPZ-60, PZ-30, PZ-29, SRPZ-37 (from the crest to the base on the foundation). In this case, data from 12/10/2019, representing the first geophysical data acquisition campaign and from 07/03/2020, representing the second acquisition campaign were used. 


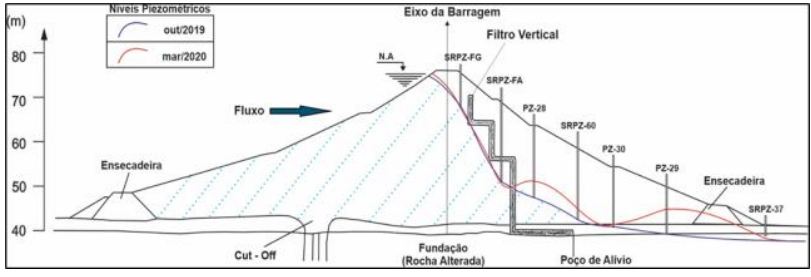

Figure 9 - Piezometric levels in a section perpendicular to the ridge, in its southern portion, with respect to seven piezometers, in the months of October/2019 (blue line) and March/2020 (red line). The direction of water flow is indicated upstream of the dam massif.

The piezometric heights measured in the month of March/2020 indicate a higher water saturation of the landfill soil, if compared to the month of October/2019. This behavior would be associated with higher rainfall rates during summer, the wettest season of the year in hot and humid climates, compared to autumn.

Another technic (Figure 10) involved comparing the water table for the same piezometers as in the Figure 9.

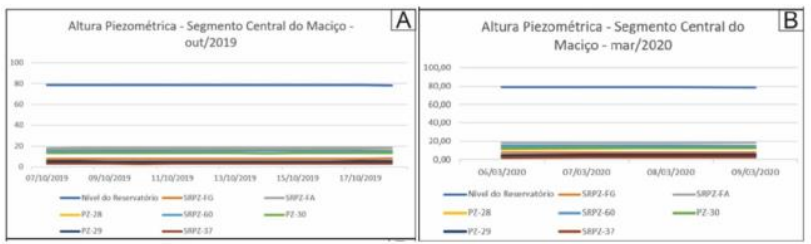

Figure 10 - Piezometric heights in the central segment of the dam massif: (A) October/2019, (B) March/2020.

In this case, the water level seems to behave almost constantly over short time scale, with little significant daily variation (on the order of centimeters to millimeters). The observed behavior reflects the nature of the compacted clay soil, predominantly impermeable, subject only to percolation of water conditioned to pore pressures, whose control is accomplished with the aid of filters, drains, and monitoring instruments.

\section{Time-Lapse ERT Inversion}

Time-lapse inversion technique measures the percentage variation of the resistivity parameter, in the same location, based on different instants of time. In this study (Figure 11), time-lapse was performed to estimate the resistivity differential between the months of October/2019 and march/2020.

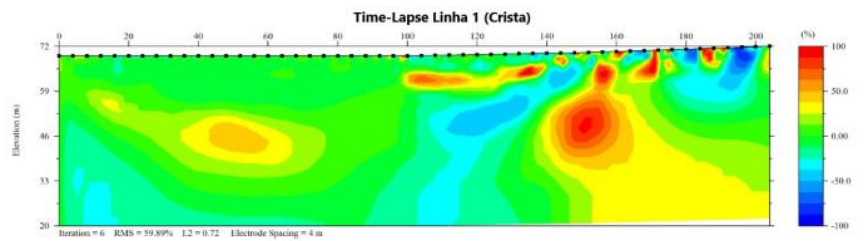

Figure 11 - Time-Lapse ERT profile for the dam's creast, in wich the percent difference in electrical resistivity is displayed.
In the Figure 11, regions with highest percentage of resistivity variation (colored in red) correspond to possible areas of fluid percolation and water accumulation (saturated soil), due to periods of intense precipitation. The blue colored regions represent exceptionally low or null percent variation, i.e., with a stable hydraulic behavior.

\section{Conclusions}

The comparison of information obtained in both campaigns aimed at detecting significant temporal changes in the hydraulic and structural behavior of the dam's slope and abutments, because of climatic variations in rainfall and river flow over a six-month period.

The research combines knowledge of applied geophysics, geotechnics, dam engineering, hydrogeology, and geology. The interpretation of the information gathered in field, therefore, was carried out in a complementary manner to the auscultation data (piezometric readings, groundwater level measurements of the dam and reservoir) and engineering data (structural design of the dam). The project also demonstrates how certain geological properties control and modulate the signals recorded from geophysical tests.

In this study, data analysis and interpretation has proved to be efficient for the proposed purpose and the methodology may be applied to landfill dams for any type of reservoir, with the main interest being the ore tailings dams.

We believe that modern, non-invasive geophysical techniques should be used in order to avoid the recurrence of dam catastrophes, especially in Brazil.

\section{Acknowledgments}

The authors wish to acknowledge and thank the financial support from the Brazilian National Research Council (CNPq) and the Rio de Janeiro State Research Support Foundation (FAPERJ).

\section{References}

AL-FARES, W. 2011. Contribution of the geophysical methods in characterizing the water leakage in Afamia B dam, Syria. Journal of Applied Geophysics, 75(3), 464471.

CASE, J. S. 2012. Inspection of earthen embankment dams using time lapse electrical resistivity tomography. Dissertation, The University of Mississippi.

DI, Q., \& WANG, M. 2010. Determining areas of leakage in the Da Ye Dam using multi-electrode resistivity. Bulletin of engineering geology and the environment, 69(1), 105109.

KEMNA, A., BINLEY, A., SLATER, L. 2004. Crosshole IP imaging for engineering and environmental applications. Geophysics, 69(1), 97-107. 
KEMNA, A., BINLEY, A., CASSIANI, G., NIEDERLEITHINGER, E., REVIL, A., SLATER, L...\& KRUSCHWITZ, S. 2012. An overview of the spectral induced polarization method for near-surface applications. Near Surface Geophysics, 10(6), 453-468.

LIN, C. P., HUNG, Y. C., YU, Z. H., \& WU, P. L. 2013. Investigation of abnormal seepages in an earth dam using resistivity tomography. Journal of GeoEngineering, 8(2), 61-70.

MINSLEY, B. J., \& IKARD, S. 2010. Geophysical Investigations at Hidden Dam, Raymond, California Flow Simulations. U. S. Geological Survey. 